\title{
BACON PURO EMPIRISTA: CONSIDERAÇÕES ACERCA DA INTERPRETAÇÃO DE KARL POPPER
}

Helton Lima Soares ${ }^{1}$

Resumo: A presente pesquisa objetiva discutir a leitura de Karl Popper sobre os escritos de Francis Bacon no que concerne ao método científico. Popper afirma que Bacon é um puro empirista, na medida em que o filósofo inglês sugere a indução como método seguro à ciência, e concebe as teorias científicas a partir da observação direta da natureza, ou seja, a partir da experiência. Mas será mesmo que Bacon pode ser considerado um puro empirista como afirma Popper? Na tentativa de responder a esta questão, apresentar-se-á leituras de comentadores de Bacon para que se possa contrapor às ideias de Popper. Nossa hipótese é de que a interpretação de Popper é válida, uma vez que se baseia em preceitos lógicos, porém acreditamos que sua análise desconsidera partes das obras de Bacon que fundamentam a interpretação de que este não pode ser considerado um puro empirista.

Palavras-Chave: Karl Popper; Francis Bacon; Método Científico; Empirismo.

\footnotetext{
${ }^{1}$ Acadêmico de Licenciatura em Filosofia pela Universidade Federal do Pará e Membro do Grupo de Pesquisa em Filosofia da Ciência. Trabalho orientado pela Prof ${ }^{a}$. Dr ${ }^{a}$. Elizabeth de Assis Dias. Email: heltondelimasoares@gmail.com
} 
Karl Popper (1902-1994), filósofo austríaco do século XX, é um crítico ferrenho da epistemologia empirista tradicional instituída a partir do século XVII, sobretudo porque o método indutivo e empírico está nas raízes das teorias da ciência desta época. Sendo Francis Bacon (1561-1626) o primeiro filósofo da modernidade a propor um método empírico-indutivo sistematizado do conhecimento científico, que preza especialmente pela experiência, este não escapa das considerações popperianas. Popper considera Bacon o fundador de um movimento que dogmatiza a ciência:

O movimento iniciado por Bacon foi um movimento religioso ou semi-religioso, e Bacon foi o profeta da religião secularizada da ciência. Substituiu o termo "Deus" pelo substantivo "Natureza", mas deixou quase todo o resto na mesma. A teologia, a ciência de Deus, foi substituída pela ciência da Natureza. As leis de Deus foram substituídas pelas leis da Natureza. O poder de Deus foi substituído pelas forças da Natureza. (POPPER, 2009, p. 142).

A leitura que Popper faz dos escritos de Bacon é estritamente rigorosa, uma vez que sua proposta metodológica e conceitual é contrária à do Lorde Verulâmio. É na obra $O$ Mito do Contexto (2009) que Popper explicita os pontos de suas considerações. Suas críticas começam ao que chama de "dogma antiteórico de Bacon", que diz respeito, inicialmente, à doutrina dos ídolos formulada no Novum Organum (1999).

Segundo Bacon, existem quatro tipos de ídolos (idola) responsáveis por formar preconceitos na mente humana; são eles: ídolos tribo, ídolos da caverna, ídolos do foro e ídolos do teatro (NOVUM ORGANUM, Livro I, XXXIX). O cientista, antes de partir para a observação direta da natureza, deve expurgar de sua mente esses obstáculos epistemológicos. Ora, Popper não acredita num método de purificação da mente, dado que não há critérios para se considerar uma ideia como preconceito. Para o filósofo austríaco, só o avanço da ciência é capaz de mostrar que as crenças ou teorias são preconceitos e uma mente purificada, nos termos em que propunha Bacon, é uma mente vazia, sem conteúdo.

Operamos sempre com teorias, mesmo que, na maior parte das vezes, delas não tenhamos consciência. [...] Não há observação "pura”, isto é, observação sem uma componente teórica. Toda a observação - e em particular toda a observação experimental - é uma interpretação dos factos à luz de uma ou outra teoria (POPPER, 2009, p. 148).

Bacon, ao propor um método em que a observação mostra-se como ponto de partida do conhecimento científico, reitera que o saber da ciência nasce na experiência; entretanto Popper afirma que o Barão de Verulam tinha conhecimento da tendência geral de interpretar as observações à luz de teorias e que, desta forma, não se poderia aprender com a experiência, uma vez que todo fato observado corroboraria aquilo que se nomeou de preconceitos. Porém, há um problema em Bacon admitir que as ideias pré-concebidas podem ser parte importante na 
lógica de seu método indutivo: com estas não se pode sustentar a noção de teorias como puramente empíricas. Segundo Popper, “a única fuga possível que [Bacon] conseguiu imaginar foi a proposta irrealizável de expurgar as nossas mentes de todas as teorias e aderir a uma observação "pura"” (POPPER, p. 149, 2009).

Outro ponto importante que Popper discorda do pensamento de Bacon é a indicação da observação e da indução como os caminhos corretos para o desenvolvimento e progresso da ciência. Sabe-se que Bacon influenciou diversos filósofos e cientistas do século XVII, entretanto suas ideias se apresentavam como guias metodológicos ainda no século XX, fato que estimulou Popper a propor um método totalmente diferente. ao se voltar sobre o que chamou de dogmas ("observacionismo" e "indutivismo") e ao explicar como entende o método baconiano, o filósofo é enfático:

\begin{abstract}
Este é o método de Bacon de observação e indução. Em breves palavras: a observação pura, sem mácula, é boa, e a observação pura não pode errar; a especulação e as teorias são más, e constituem a causa de todo erro. Mais especificamente, fazem-nos ler mal o Livro da Natureza - ou seja, interpretar mal as nossas observações. [...] O observacionismo de Bacon e a sua hostilidade a todas as formas de pensamento teórico foram revolucionários e sentidos como tal. Tornaram-se o grito de guerra da nova religião secularizada da ciência e o seu dogma mais acarinhado. Este dogma exerceu uma influência quase inacreditável tanto na pratica como na teoria da ciência, influência essa ainda forte nos nossos dias (POPPER, 2009, p. 145).
\end{abstract}

A caracterização de Bacon como puro empirista segue daí. Ora, se Bacon sugere uma ciência empírica que busca, primeiramente, uma exclusão das "especulações metafísicas" e que parte, necessariamente, de observações puras da natureza, observações que gerarão as futuras teorias universais, então este pode ser proclamado um puro empirista, até mesmo por considerar a ciência o verdadeiro conhecimento capaz de conceder ao homem o domínio da natureza, e tendo este conhecimento o pressuposto de partir de observações empíricas da realidade, logo o conhecimento verdadeiro se inicia na experiência; o próprio caráter das leis universais "representa, pois, uma generalização da experiência" (CHIBENI, ano, p. 2). Oliva alega que "não podemos perder de vista que a metodologia baconiana, além de pretender ser uma ilimitada arte de invenção, apresenta-se também como um aparato de justificação rigorosamente legitimador das alegações empíricas de conhecimento" (1990, p. 16). Acreditamos, assim, que Popper compartilha desta mesma concepção.

\title{
Possíveis críticas à interpretação de Popper
}

Destacaremos agora posições em relação ao pensamento de Bacon que questionam a interpretação de Popper. 
Paolo Rossi, importante comentador de Bacon, escreve em Francis Bacon: da Magia à Ciência que a doutrina dos ídolos é bem mais complexa, existindo os ídolos inatos ao homeme os ídolos adquiridos. Rossi afirma ainda que a doutrina dos ídolos podia não estar fechada, pois havia a possibilidade de Bacon descrever outros gêneros que considerasse pertinentes. Tomando como referência a descrição feita por Bacon no Novum Organum, Rossi explicita que:

Os ídolos adquiridos penetram na mente vindos "das seitas dos filósofos ou das más formas das demonstrações". Este tipo de ídolos é eliminável com dificuldade; os outros não são de modo algum elimináveis: permanece tão-somente a possibilidade de indica-los, de descrevê-los de tomar consciência dessas forças que insidiam a mente humana (2006, p. 341).

Considerando a interpretação de Rossi, pode-se dizer que Bacon tinha consciência de que a mente não podia ser esvaziada, sem conteúdo. Os ídolos adquiridos (ídolos do teatro) devem passar por uma forte crítica, afim de que estes, com muito esforço, sejam eliminados. Os ídolos pertencentes à natureza humana (ídolos da tribo, ídolos da caverna e ídolos do foro) devem ser identificados para que se conheça a causa dos erros e, assim, traçar procedimentos seguros para a prática metodológica científica (ZATERKA, 2004, p. 109). Faz-se necessário voltar o olhar aos ídolos do foro, que dizem respeito as relações sociais mantidas pelo uso da linguagem, posto que Bacon os considera pertencentes ao plano da natureza humana, pois o homem não pode isolar-se e não viver em sociedade (ROSSI, 2006, p. 342).

No aforismo L do Novum Organum Bacon afirma que os sentidos provocam as maiores confusões ao intelecto, confusões capazes de contaminar as coisas mais importantes. Zaterka (2004) anuncia que os sentidos na obra do Lorde Verulâmio são postos por dois vieses, um positivo e outro negativo. Segundo a autora, pelo viés positivo os sentidos são a comissão de frente de um empreendimento epistemológico novo; pelo sentido negativo os sentidos são causadores de preconceitos. A comentadora acredita ser importante dar ênfase a essas duas concepções pelas quais Bacon se dirige aos sentidos, pois elas mostram "o real estatuto da relação razão/sentidos no projeto baconiano" (p. 107, 2004).

Os comentadores de Bacon, quando defendem que o filósofo não é um puro empirista e ao discorrerem sobre o papel da razão e da observação na concepção baconiana, firmam-se no seguinte aforismo:

Os que se dedicaram às ciências foram ou empíricos ou dogmáticos. Os empíricos, à maneira das formigas, acumulam e usam as provisões; os racionalistas, à maneira das aranhas, de si mesmos extraem o que lhes serve para a teia. A abelha representa a posição intermediária: recolhe a matéria-prima das flores do jardim e do campo e com seus próprios recursos a transforma e digere. Não é diferente o labor da verdadeira filosofia, que se não serve unicamente das forças da mente, nem tampouco se limita ao material fornecido pela história natural ou pelas artes mecânicas, conservado intato 


\title{
REVISTA APOENA - Per. dos Dis. de Fil. da UFPA \\ Belém, 2019, V. 1, N.1.
}

na memória. Mas ele deve ser modificado e elaborado pelo intelecto. Por isso muito se deve esperar da aliança estreita e sólida (ainda não levada a cabo) entre essas duas faculdades, a experimental e a racional (NOVUM ORGANUM, Livro I, Aforismo $\mathrm{XCV})$.

A partir do aforismo supracitado, é possível perceber que a concepção de Bacon não é a de um empirismo ingênuo, como assinala Popper; a observação, a razão e o experimento caminham juntos, numa rede metodológica na qual os elementos constituintes são inseparáveis. A razão tem um papel fundamental, uma vez que é a responsável por sistematizar os dados colhidos das observações e por propor teorias gerais para a ocorrência de experimentos (ZATERKA, p. 137-138, 2004). A partir dessas informações, pode-se, então, considerar Bacon não como puro empirista, mas como um filósofo que preza pela experiência e que ao mesmo tempo reconhece a funcionalidade da razão. Popper, talvez, tenha pecado ao considerar o empirismo baconiano como ingênuo. Vale, ainda, destacar a declaração de Barreto \& Moreira:

\begin{abstract}
Bacon preconizava, para a formulação do novo método científico, o abandono definitivo do princípio da autoridade e a aceitação, como fonte do conhecimento, da experiência e da razão. Experiência e razão juntas, num equilíbrio harmônico, sem predomínio de uma sobre a outra, comporiam as pilastras do novo método: a indução experimental. Bacon, portanto, defende a necessidade de que o cientista se afaste do empirismo radical e do racionalismo exagerado (1993, p. 50).
\end{abstract}

\section{Considerações Finais}

Após breve análise das interpretações aqui expostas, consideramos que a interpretação de Karl Popper é tão válida quanto a dos comentadores específicos de Francis Bacon. Popper, talvez, tenha feito um apanhado geral da obra baconiana, podendo ter desconsiderado a possibilidade de Bacon ser um filósofo que prezasse pela racionalidade, inclusive porque as passagens em que Bacon expressa sua possível posição harmônica entre o racionalismo e o empirismo são pontuais, podendo passar despercebidas em sua obra. Popper buscou uma certa coerência nas obras de Bacon, o que nos leva a pensar, ainda, que pode haver uma contradição entre a doutrina dos ídolos e o método indutivo propostos por este último.

Por outro lado, uma análise dessas passagens pontuais aos quais os pesquisadores da filosofia de Bacon se propõem a esclarecer é essencial tanto para a compreensão da obra do filósofo inglês, quanto para fins de empreendimentos de pesquisa. Por fim, reafirmamos que as interpretações aqui expostas são válidas e que cada uma segue uma perspectiva diferente. Se tratando de Popper, sua interpretação deve ser vista como importante, mas também limitada em certos aspectos; porém, não acreditamos que uma possível análise mais profunda feita pelo filósofo pudesse mudar suas ideias, já que sua crítica se volta, principalmente, ao método indutivo que é formulado na Antiguidade e passar por uma reelaboração no século XVII por 
Bacon. Tal método conserva a mesma estrutura lógica de pesquisa científica, sempre partindo da observação, mesmo que se admita que em passos seguintes a razão exerça um papel importante de criticidade e que Bacon tenha enfatizado isso, ainda sim o conhecimento da ciência nasceria na observação direta, por meio de coletas de dados, da/na natureza.

\section{BIBLIOGRAFIA}

BACON, Francis. Novum Organum ou verdadeiras Indicações acerca da Interpretação da Natureza. São Paulo: Editora Abril Cultura, 1999.

BARRETO, José Anchieta Esmeraldo; MOREIRA, Rui Verlaine Oliveira Moreira. $O$ Problema da Indução: O Cisne Negro Existe. Fortaleza: Edição dos Autores, 1993.

CHIBENI, S. S. O que é ciência? Texto didático. Departamento de Filosofia da Universidade Estadual de $2004 . \quad$ Campinas. $<$ http://www.unicamp.br/ chibeni/textosdidaticos/textosdidaticos.htm>. Acessado em 11 maio 2018.

OLIVA, Alberto. "A Hegemonia da Concepção Empirista de Ciência a Partir do NovumOrganon de F. Bacon”. In: OLIVEIRA, A. (Org.). Epistemologia: A Cientificidade em Questão. Campinas: Papirus, 1990. p. 11 - 33. x

POPPER, Karl. O Mito do Contexto: Em Defesa da Ciência e da Racionalidade. Lisboa: Ed. 70, 2009.

ROSSI, Paolo. Francis Bacon: da Magia à Ciência. Londrina: Eduel; Curitiba: Editora da UFPR, 2006.

ZATERKA, Luciana. “Alguns Aspectos da Filosofia da natureza de Francis Bacon”. In: A Filosofia Experimental na Inglaterra do Século XVII: Francis Bacon e Robert Boyle. São Paulo: Associação Editorial Humanitas: Fapesp, 2004. 